\title{
Translation of semiotics into translation theory, and vice versa
}

\section{Susan Petrilli}

Reflection on sign processes and translation processes contributes to a better understanding of the problems involved in both and orients relative research methodologies. The dynamics involved is the same and concerns the dialogical relation between one sign and another where the latter as an interpretant confers meaning and sense on the preceding, the interpreted. Though different disciplines, sign theory and translation theory study the same process, albeit from different perspectives. Semiotics and translation act as interpretants of each other illuminating different aspects of the signs forming these processes, their specificities and interrelatedness. According to Thomas Sebeok and his 'global semiotics', all signs, verbal and nonverbal, are part of an overarching sign network. Considering that interpretation is translation, that the relation between interpreted sign and interpretant sign is a translation relation, that interpretants defer to each other in open-ended semiosic chains, global semiotics evidences the translational nature of semiosis, therefore the translational vocation of semiotics. Sebeok belongs to a tradition in sign studies that extends from Locke to Peirce and includes authors like Welby, Jakobson, Bakhtin, Morris. All deal with translation, whether directly through their sign theory (Welby, Jakobson), or indirectly with their reflections on dialogue and the relation between reporting and reported discourse (Bakhtin), or whilst searching for signs to talk about signs (Morris). Global semiotics opposes anthropocentric and glottocentric approaches to the life of signs: the entire biosphere is perfused with signs. As a general sign science semiotics has a propensity for dialogic encounter and translation. As an interpretive/translational phenomenon and thanks to its specificity as artistic discourse evolving in the 'great time' (Bakhtin), literary discourse best evidences the dynamics of semiosis and together the properly human, therefore the questions of dialogic otherness, responsive understanding, responsibility/responsivity, translatability/intranslatability, iconicity, visibility/ invisibility, similarity/dissimilaritry, the paradox of translation.

KEYWORDS Semiosis; Otherness/Alterity; Dialogism; Responsive understanding; Similarity

\section{Semiotics and translation theory beyond anthropocentrism and glottocentrism}

The question we wish to explore is whether semiotics can be translated into translation theory and whether translation theory can be translated as semiotics. This does not mean to suggest that translation theory and semiotics are the same thing. These two different disciplines are intent upon exploring the same process, i.e. that of semiosis, of the infinite deferral among signs, but under different aspects. Just as I say that Italian can be translated into English and vice versa does not mean to say that English and Italian are the same thing, to claim that there is a relation of translation between semiotics and translation theory does not at all mean to establish a relation of identification between 
the two terms. Semiotics and translation theory are different disciplines, but between them there exists a relation of translation understood as the possibility of explanation and development as they respond to and interpret each other.

Translation across the infinite variety of different domains that constitute the semiosphere characterizes the semiotic perspective itself, which traverses both the natural sciences and the human sciences focusing on signs at once in their specificity and interrelatedness: signs of 'nature' and 'culture', human signs and nonhuman signs, verbal signs and nonverbal signs, natural languages and artificial languages, signs at high levels of plurivocality and dialogism and univocal and monological signs (or signals), signs at varying degrees of indexicality, symbolicity and iconicity, signs of the conscious and the unconscious.

The universe is perfused with signs, indeed, as Charles S. Peirce hazards (CP 5.448, n. 1), is perhaps composed exclusively of signs. Thomas A. Sebeok also contemplated the whole universe as a complex global sign. In Peirce's words, 'a vast representamen, a great symbol... an argument [...] necessarily a great work of art, a great poem [...] a symphony [...] a painting' (CP 5.119). Nor did such an approach mean to claim intellectual omnipotence, as intimated by some. Sebeok knew that to understand any one particular type of sign - such as the verbal - it was necessary to view that sign as part of the whole of which it is a part.

Sebeok envisaged a sort of global dialogue and dialogic globality interconnecting signs in a huge semiosic 'network' or 'web' (Sebeok 1975, 1995) where signs act as interpretants of each other beyond the strict limits of anthroposemiosis. He dubbed his ecumenical perspective with the apt expression 'global semiotics' (Sebeok 2001).

A fundamental axiom posited by Sebeok is that signs and life, human and nonhuman, converge so that to maintain and reproduce life and not only to interpret it at a metadiscursive level, necessarily involves signs (Petrilli 2014: 306-311). This position reveals an intimate connection between the biological and the semiosic and, inevitably, between the sciences that study them, biology and semiotics. Semiotics with a claim to globality must keep account of its a priori status as a general science of signs and of its constitutive propensity for dialogic encounter and translation.

Global semiotics accomplishes the overarching vision of 'interpretation semiotics', where interpretation means translation, translation from one sign into another sign, its interpretant. Interpretation semiotics attributes an inevitable and essential relation with the interpretant to the sign. The sign only subsists in relation to a given interpretant; it orients itself toward the subject according to a specific modality as expressed by its interpretant. Furthermore, the relationship between the interpreted sign and the interpretant sign is never one of convergence, repetition. ${ }^{1}$ As Peirce says, the interpretant always adds something new as it shifts the sign toward the possibility of encounter with yet another interpretant sign.

The relation between interpreted and interpretant is a relation of translation, characterized by the tendency toward boundlessness, unlimitedness. Peirce talks of unlimited sequences of interpretants, open-ended chains of deferral, infinite semiosis. And Sebeok on his part, extending further Peirce's idea (Watt 2011), develops this possibility of opening and infinite deferral to a maximum degree. In fact, with global semiotics the translational nature of semiosis, therefore the translational vocation of semiotics are emphasized owing to the search by semiotics for interpretants that are always more distant, beyond the boundaries of the human and the conventional - which are also the boundaries of linguistics - to which it had been relegated by semiology.

Roland Barthes was perfectly right when in his Éléments de sémiologie (1964), with regards to the relationship between linguistics and sémiologie (as conceived by Saussure), he maintained that semiology was a part of linguistics and not vice versa. But with Sebeok and his 'global semiotics', semiotics fully recovers its dialogical and interpretive-translative character and emerges once again as a far broader and far more comprehensive sphere with respect to linguistics. Allusion here is not only 
to the linguistics of the linguists, but also to Charles Morris's (1946) description of linguistics which he extended to the study of all that which he called 'language', therefore to all human languages, verbal and nonverbal. This conception of language is connected to the species-specific human primary modelling device also rightly denominated 'language' by Sebeok $(1986,1994)$, distinct from 'speech'.

Evidently, global semiotics thus described presupposes the critique of anthropocentrism and glottocentrism, which includes all those trends that turn to linguistics for their sign model. Verbal signs constitute only a tiny sector of the signs on our planet. And yet, they have been so exalted in the course of human history - especially in the West - that we must speak of 'arrogance', a form of arrogance closely connected with the anthropocentric vision, recurrent not only in the realm of common sense and in philosophy, but also in the sciences.

All the same, an explanation, which of course is not a justification, for exalting the verbal sign, a human prerogative, is translatability, precisely. All signs implicated in the great semio(bio)sphere can be translated into verbal signs. This is what such expressions as 'omniformativity' (Hjelmslev), 'universality of the noetic field', 'boundlessness of human language' (Chomsky), 'omniformative character of verbal signs' (De Mauro) all allude to (cf. Petrilli 2014: 304-306).

A dynamic approach to sign and language inevitably involves reflection on the role of translation. Victoria Welby, inventor of significs, as she calls her theory of meaning (cf. Petrilli 2009, 2015), is a pioneer on this front, having developed the latter in close association with translation theory. Welby understands "translation" not only in the obvious sense of the transferral from one language to another, i.e. interlingual translation, but also of the transferral of verbal signs into nonverbal signs and vice versa, i.e. intersemiotic translation, and of verbal signs into other verbal signs of the same language, i.e. intralingual translation. She takes translation as a method of interpretation and understanding, and our mental activities as nothing short of automatic translational processes. As foreseen by Peirce's own conception of the sign, the meaning of a sign is given in the relation to another sign that interprets it. In this sense the sign is in translation. Semiosic fluxes and signifying processes converge with translation/interpretation processes; semiosis is a translation/interpretation process.

Welby's theory of translation is an important aspect of her significs which she describes as a 'philosophy of significance', 'philosophy of interpretation' and 'philosophy of translation'. Moreover, with reference to communication in the human world and specifically to verbal language, her theory of translation is closely connected to her reflections on figurative language and on the role of metaphor, analogy and homology in expression and understanding. The acquisition of knowledge implies the capacity to establish links and connections in translational, interpretive processes (Welby 1983 [1903]: 89, 150, 161).

The more a sign translates into ever more numerous spheres of human knowledge and experience, the more its significance and ultimate value is enhanced. Different aspects of the processes of translation are expressed by the words transference, transformation, transmutation, transfiguration, transvaluation. Significs aims to develop critical awareness, the linguistic conscience, to empower and somehow master translational processes as the very condition for understanding. The sense, meaning and significance of an utterance are understood and enhanced through ongoing translational processes.

With reference to the question of subjectivity, the self emerges from intersubjective interpretive-translative practices involving the other; cultures are polylogic, the open, unfinalized expression of ongoing translational processes among different voices and worldviews; as sign activity of the 'meta' order, the sciences involve translational processes across different sign systems and orders of discourse (Kumar and Malshe 2005).

Though not thematized directly, translation is also essential to Mikhail M. Bakhtin's conception of interpretation, understanding and dialogism. His theory of language and meaning is rich in suggestions for a theory of linguistic and cultural translation (Ponzio 2005; Torop 2002), such that we may 
claim that translation is central in the work of Bakhtin and his circle of collaborators (Bachtin e il suo Circolo 2014; Zbinden 2006). From this point of view Voloshinov's observations in Marxism and the Philosophy of Language on the problem of understanding are emblematic when he claims that:

any true understanding is dialogic in nature. Understanding is to utterance as one line of a dialogue is to the next. Understanding strives to match the speaker's word with a counter word. Only in understanding a word in a foreign tongue is the attempt made to match it with the 'same' word in one's own language. (Voloshinov 1986 [1929]: 102)

Rejecting the 'scientific fictions' of linguistics (including Saussure's), which identifies two partners in speech communication, an active speaker and a passive listener, Bakhtin argues:

The fact is that when the listener perceives and understands the meaning (the language meaning) of speech, he simultaneously takes an active responsive attitude toward it. He either agrees or disagrees with it (completely or partially), augments it, applies it, prepares for its execution, and so on. And the listener adopts this responsive attitude for the entire duration of the process of listening and understanding, from the very beginning - sometimes literally from the speaker's first word. (Bakhtin 1986 [1952-53]: 68)

The interpretant of active responsive understanding is specific to the sign; whereas the interpretant of identification is specific to the signal. The utterance, the dialogic word, the text call for responsive understanding; whereas the sentence, object of study of traditional linguistics, abstract and isolated from the real processes of dialogic interactive communication, simply calls for identification.

Interpretation, in the sense of responsive understanding, converges with translational processes at high degrees of otherness and creativity, whether it is a question of interpreting texts across different historical-natural languages or within the same language. Different types of interpretive-translative processes at varying degrees of otherness and responsiveness are present together in any given instance. For example, similarly to translation, whether intralingual or interlingual, the responsive interpretation of an utterance will depend on the capacity to identify syntactical structure. The utterance 'I read your letter to Frank' can be disambiguated either in the sense that the letter was addressed to Frank and I read it, or in the sense that the letter was addressed to somebody else and I read it to Frank. The capacity to disambiguate, which Noam Chomsky (1956) attributes to deep structures, consists in the generative capacity of interpretants that are not necessarily foreseen by the system of language, but rather are connected with the utterance, with its verbal and situational context and with translational relations of the endosemiotic and intersemiotic orders.

\section{Iconicity, dialogism and otherness in textual translation}

From a semiotic perspective we know that the text is made of sign material. This means that the text, any text whatsoever, is already a translation in itself, is already an interpretation, in fact, a sign is such thanks to its interpretant. Translation across languages is a specific case of translation across sign systems, what we may also call 'semiosystems', internally and externally to the same historical-natural language. And translation across languages is only possible on the basis of language understood as a modelling device. Language as modelling is an a priori condition for language as communication, that is, for verbal expression, speech which, instead, arises originally for communication and thanks to the predominance of iconicity in the relation among signs.

With reference to literary translation, if we understand 'fidelity' in terms of creativity and interpretation, and not just of imitation, repetition, reproduction of the same, of the 'original' text, a literal copy 
in another language, the translatant text must establish a relation of alterity with the text object of translation. ${ }^{2}$ The greater the distancing in terms of dialogic alterity between two texts, the greater is the possibility of creating an artistic reinterpretation through another sign interpretant in the potentially infinite semiosic chain of deferrals from one sign to the next, to which belongs the so-called 'original'. With reference to Peirce's general theory of signs, in particular his triad 'icon', 'index', and 'symbol', if a translation is to be successful in terms of creativity and interpretation, the relation between the text object of translation and the translatant text must be dominated by iconicity. A translation must be at once similar and dissimilar, the 'same other' (see Petrilli 2001). This is the paradox of translation. Therefore a text is at once translatable and untranslatable. This is the paradox of language.

The question of similarity is central to translation. In translation the relation between the text and that to which it refers, the original text, presents itself in terms of similarity. This similarity between the translation, that is, what we could call the 'translatant text' and the original text, the 'translated text', is an iconic similarity. The translatant text is predominantly an iconic sign, an icon.

The icon is one of the three types of signs identified by Peirce, the other two being the index and the symbol. The index is a sign that signifies its object by a relation of contiguity, causality or by some other physical connection. In Peirce's typology the symbol is the sign mainly in consequence of the mediation of a habit, or convention (see CP 4.531). Signs that are exclusively symbols, icons or indexes do not exist in the real world. The icon is never conceived as a pure icon but is always more or less mixed with indexicality and symbolicity, and vice versa. Consequently, iconicity is always, in Peirce's words, more or less degenerate (in a mathematic sense). This implies that icon, index, and symbol represent different levels of degeneracy of the sign, instead of being three separate and autonomous classes of signs.

The icon is characterized by a relation of similarity between the sign and its referent. However, similarity is not sufficient to determine an iconic sign. Twins look similar but they are not signs of each other. My reflex in the mirror looks like me but it is not an iconic sign. For iconic signs to obtain, the effect of convention, habit, social practices or special functions must be added to similarity. Iconic similarity is a special kind of similarity: it is an abstraction on the basis of a convention, and it privileges only certain traits of similarity. Similarity of a banknote to another banknote worth $\$ 50$ is no doubt a sign that the first banknote too is worth $\$ 50$. But if similarity is complete to the point that the serial numbers of both banknotes are identical, we have a false banknote that cannot carry out a legitimate function as an iconic sign on the money market.

All the same, as Peirce suggests, the icon is the most independent sign of all from both convention and causality/contiguity: 'an icon is a sign which would possess the character which renders it significant, even though its object had no existence; such as a lead-pencil streak as representing a geometrical line' (CP 2.304). Peirce analyzes the iconic sign in terms of 'firstness' or 'originality': the icon is an 'original sign', a sign whose significant virtue is due simply to its Quality (CP 2.92). Iconicity implies otherness as absolute otherness, and not the relative otherness of indexicality.

As in sacred icons, the icon maintains its otherness and resists converging with the directness of representation, with the boundaries of the object. Unlike the idol, the icon evades the logic of identity, of the totality and emerges in terms of figuration, depiction, presentation and not representation, but presentation of an absence, of the absolute other. As the great philosopher Emmanuel Levinas (1994: 123-148) would say, the icon with respect to its object is its shadow, its double, as Dostoevksy would say, in other words, its otherness, absolute otherness.

Translation is indirect discourse masked as direct discourse, all the same it is distanced from its (author-)translator. In fact, the translator says ' $\mathrm{l}$ ' and nobody identifies him or her with the I of discourse, even in the case of oral and simultaneous translation. The Ambassador says: 'Grazie per l'accoglienza, sono davvero onorato di essere qui'; and the interpreter translates: 'Thank you for receiving me, I am indeed honoured to be here'; and nobody would dream of thinking that it is the 
interpreter who is grateful or honoured. Numerous misunderstandings can and effectively do occur in an interpreter's translation. A hilarious episode occurred in relation to President Carter's visit to Poland when his interpreter told the audience not that I/Carter was interested in their desires for the future, but that he wanted to know them carnally. ${ }^{3}$ In any case, one thing is unequivocal and this is that even if the interpreter translates in the first person (direct discourse), and not in the third (indirect discourse), nobody would dream of thinking that it's the translator who wants the carnal experience! In the same way, no reader of an essay, novel or poem would ever attribute the author's words to the translator, as much as the latter normally reports the other's discourse in the form of direct discourse.

From this point of view and contrary to prejudice about the possibility of translating literary texts - especially a poetic text - the capacity for exotopy, distancing, extralocalization (Bakhtin), and the iconic relation of similarity that regulates translation as translation, somehow makes translation a privileged place for the orientation of discourse towards literariness. Such characteristics shared by the literary word and its translation in fact render them less distant from each other than would be commonly expected.

The question of translation may either concern 'simple' texts or 'complex' texts. In our view this distinction corresponds to that proposed by Bakhtin in The Problem of Speech Genres (1986 [195253]: 60-102) between 'primary genres' and 'secondary genres': 'simple texts' belong to primary genres, that is, to those discourse genres that are not part of literature; on the contrary, 'complex texts' are those of literary genres. For that which concerns problems of text semiotics, including the problem of translation, texts from secondary and 'complex' genres, as Bakhtin also calls them, shed light on primary or 'simple' genres and not vice versa, just as the anatomy of human beings helps to understand that of the monkey's, and not vice versa. This is also Walter Benjamin's perspective in his essay The Task of the Translator (1968 [1923]). In Bakhtin's words:

A one-sided orientation toward primary genres inevitably leads to a vulgarization of the entire problem (behaviorist linguistics is an extreme example). The very interrelations between primary and secondary genres and the process of the historical formation of the latter shed light on the nature of the utterance (and above all on the complex problem of the interrelations among language, ideology, and world view). (Bakhtin 1986 [1952-53]: 62)

The iconic relation between the text and that which it refers to is particularly obvious in the case of literary texts and of art texts in general, which are characterized by the relation of similarity among signs in terms of 'depiction', 'figuration', and not of mere imitation, representation, identification, or unification, that is, not as a mere copy in another language. Evoking Paul Klee, the text - literary, pictorial, artistic in general - does not picture or figure the visible (as instead occurs with theatrical texts in theatre performances or representations), but renders the invisible visible: per invisibilia visibilia, according to an ancient formula of the Fathers of the Church and the 2nd Nicene Council. It follows that the literary text, and more broadly the artistic text, can be characterized in terms of iconicity, that is, as an icon rather than as an idol (cf. L. Ponzio 2000, 2002, 2009). This means that, in so far as it is an icon, the artistic text gets free of the status of eidolon, that is, from the idolatory of a world that has been objectified and reified. The shift is from the idols of representation, where the subject and the object are frozen by the gaze and reified, to the icons of figuration, of depiction, according to a movement forward without return, a one-way, open trajectory according to the logic of alterity.

The eidolon (eido, video) gives itself in presence and is represented, in other words, it is captured by the gaze and possessed by the self, the subject. The idol offers itself directly to the gaze, satisfies the gaze, and the gaze, in turn, remains completely anchored to the visible, without ever attempting to surpass it or transcend it. The icon implies the capacity for transcendence, for surpassing boundaries of the visible, of the obvious, of representation. From sight to listening, listening to the other: this is the process of reading; this is also the process of translation. 
As is obvious, to translate is not to decodify, nor to decipher, but to interpret. It follows that a semiotics of interpretation is a necessary basis for translation theory. And we know that the question of the translation of a text must be connected to the problem of the meaning of a sign. In fact, as Peirce, Welby and Bakhtin (among others) clearly demonstrated, meaning is not in the sign but in the relation among signs, whether the signs of a defined system, like those forming a code, a langue, or the signs of dynamic interpretive processes, which know no boundaries in the transition from one type of sign to another, from one sign system to another.

The more interpretation is not mere repetition, literal translation, synonymic substitution, but rather reelaboration, explanatory and creative reformulation, interpretation-translation that takes a risk given that it does not appeal to a pre-established code with its alibis and guarantees, the higher the degree of iconicity, of firstness and originality regulating interpretive-translative processes, and the more these are capable of fully rendering the meaning of a sign.

The identity of the sign calls for continuous displacement; each time the sign is interpreted-translated it becomes other, it is in fact another sign; the 'same other', as described above, which acts as an interpretant of the preceding sign. The sign's identity is achieved through its metempsychoses, through its translations-transmigrations from one sign to another. Identification of a sign is not possible if not by exhibiting another sign.

Meaning coincides with the interpretive trajectory which knows no boundaries of a typological or systemic order. This is particularly obvious when translative processes involve interpretants, whether verbal or non-verbal, belonging to another language, to another linguistic-cultural modelling system.

To translate across texts (whether this implies crossing over different historical natural languages or different languages within a single historical natural language) involves amplifying this movement, enhancing the iconic dimension of the relation among signs as signifying potential increases. This means to enhance the relation of absolute otherness and creativity between the interpreted sign and the interpretant sign, ${ }^{3}$ between the text object of translation and the interpretant, 'translatant' text as we search for and invent new interpretants to develop the meaning of the preceding sign, of the preceding text, in terms adequate to our times, to a new signifying context.

The relation between interpreted sign and interpretant sign is not decided or dominated by constriction, by deduction as in the indexical relation. Deductive logic is replaced by associative logic, hypothetical, abductive logic, which is the logic of translation understood as reading-writing, it involves active participation and answering comprehension at the highest degree. As Barthes observed (1982, see also 1993-95), to read means to translate and to re-write. Translation across languages further enhances the associative and personal character of the reading/writing (re-writing) process, and contributes to freeing the text from a single type or system of signs. This is the task of translation. Translative processes across languages evidence the dialogic intertextuality inherent to texts, such that textual practice itself in a single language is already an exercise in translation (see also Ponzio 2007).

A translation proposed by Antonin Artaud, translator of Lewis Carroll, is a case in which the text that comes after the original claims to be first, indeed claims to be the original itself. In this case, the translation interrogates the original, asserting its difference with respect to the original, the prescribed text. Here, not only does the translation dispute the original, but it also disputes the language into which it is translated, questioning the logic of discourse, the order of representation.

In L'arve et l'aume, a translation of the chapter on Humpty Dumpty in Alice's Adventures in Wonderland, Artaud works through Carroll's text (to read is 'to read through'), and does so not only in terms of a cruel antigrammatical enterprise against Carroll himself but also against the French language (Petrilli 1999). This is a case of translation where 'existence' and 'flesh', body and life are all at stake in the process, as in the theatre of cruelty. Word-play in Carroll does not go beyond a caricature of the exchange relation between signified and signifier. Carroll does not succeed in denouncing the hypocrisy and repression upon which the exchange relation is based. Nor does he deal with social 
structures, the mechanisms of production, the ideological assumptions to which exchange is functional. Carroll glances at the looking glass, but keeps away from the double, the shadow which he catches sight of indistinctly, only to produce an infinity of heartless, psychic trickeries, an affected language.

As observed by Gilles Deleuze, the battle of the deep, its monsters, the mix-up of bodies, turmoil, subversion of order, encounter between the bottommost and the elevated, food and excrement, the eating of words, the underground adventures of Alice's Adventures Underground (which is the original title of Alice's Adventures in Wonderland), all this is supplanted by a play of surfaces: instead of collapse, there are lateral sliding movements (cf. Deleuze 1996: 37-38). Consequently, by comparison with Artaud's antigrammatical enterprise, Carroll's text is described as a bad imitation, a vulgar reproduction. The presumed original is only an edulcorated plagiarism, devoid of the punch and vigour of a work first written by Artaud. Indeed, Artaud wished to add a post-scriptum to L'arve et l'aume notifying the net sensation that he had himself first conceived and written the poem on fish, being, obedience, the sea, and God, revelation of a blinding truth (all of which is included in his translation of Carroll), centuries earlier, only to rediscover his own artwork in the hands of Carroll.

L'arve et l'aume: on the one hand, matter (purport) as understood by Louis Hjelmslev, on the other, human 'language' producing interpreteds and interpretants on the plane of content and expression. Similarly to Hamlet's cloud which changes aspect from one moment to the next, sign work invests matter, as understood by Hjelmslev, with different forms and it is on matter thus understood that every historical-natural language traces its specific subdivisions. In the same way, as regards linguistic work deposited in the different historical-natural languages, like sand which can be put into different forms, like a cloud which can take different shapes, matter may be formed or restructured differently in different languages (cf. Hjelmslev 1961, §13, Expression and Content). In spite of its alterity with respect to a given configuration, in spite of other possibilities, matter always gives itself as signified, it obeys a form and presents itself as matter. 'Obey' is a central verb in L'arve et l'aume.

The stiffening, the ossification of words, words that codify, block and paralyze thought, this is but one aspect of the general sclerotization of human signs. Instead, these must be restored the forgotten resources of language understood as an infinite modelling process, as writing. The consequence of such sclerosis, of such hardening and petrification, as claimed by Artaud in Le Théâtre et son Double, is that culture on a whole overwhelms life, dictating law to life instead of being a means to understanding and practicing life: 'Quand nous prononçons le mot de vie', specifices Artaud, 'faut-il entendre qu'il ne s'agit pas de la vie reconnue par le dehors des faits, mais de cette sorte de fragile et remuant foyer auquel ne touchent pas les formes' (Artaud 1964 [1938]: 19). On the one hand, life thus understood, arbre; 'matrix matter' (Carlo Pasi in Carroll 1993: 78), larva, embryon, egg; on the other, forms susceptible to petrification, aume, the being that human life has become.

To a petrified culture that perseveres in self-reproduction, there corresponds a petrified conception of theatre, theatre of representation, petrified theatre. But theatre has its shadow, that forms its double: 'Mais le vrai théâtre parce qu'il bouge et parce qu'il se sert d'instruments vivants, continue à agiter des ombres où n'a cessé de trébucher la vie' (Artaud 1964 [1938]: 18). The withering of verbal and nonverbal language, its limitation, has led to the loss of the relation to the shadow, to life, to the body. Official language must be broken in order to reach life, the human being's habitual limits must be refused, the boundaries of so-called reality must be infinitely broadened, beginning from the reconstruction of theatre, the specialized place of representation. This requires preparation, calculation. We cannot be content with being 'simples organes d'enregistrement' (lbid: 133).

Being is repetition, victory over living, over the alterity of the body. Being is life which perservering in being, in self-repetition, on the level of words as well, in reconfirming itself, withdraws from life; conatus essendi, which economizes on itself, does not expose itself, does not want risks, preserves itself. Being is the present which by restraining itself, keeping itself aside, in reserve, for the sake of identity ends up losing itself. Being is death caused by obstination of presence, death as repetition. 
As Jacques Derrida says, to refuse death as repetition is to assert death as expenditure, waste, present and without release. In this sense the theatre of cruelty could be considered as the art of difference and of expenditure without economizing, without reserve, without release and without history. Plato criticizes writing as body, Artaud as cancellation of body, of live gesture which only ever takes place but once (cf. Derrida 1961: xxx-xxxi).

In Artaud's translation of Humpty Dumpty, the translatant text exceeds the text claimed to be the 'original' and reunites with the matrix matter, the arve, through an act of cruelty - which had already been calculated and practiced for some time on the scene of the theatre of cruelty, even before having encountered this text by Carroll - against the text, against the English language, which Artaud knows well, and against the French language. The result is a metamorphosis-rebirth in a text that claims to be more original that the original text, because it carries itself over to and exposes itself to its very own origin more than the original had ever risked doing.

This gives rise to a sensation of maximum proximity among the two texts, which Artaud signals in his post-scriptum, but also of their maximum distancing and difference. 'Car on ne se rencontre pas avec un autre, like Lewis Carroll in his poem Jabberwocky in Humpty Dumpty, 'sur des points comme; être et obéir ou vivre et exister. Mes cahiers écrits à Rodez pendant mes trois ans d'internement, et montrés à tous le monde, écrits dans une ignorance complète de Lewis Carroll que je n'avais jamais lu, sont pleins d'exclamations, d'interjections, d'abois, de cris, sur l'antinomie entre vivre et être, agir et penser, matière et âme, corps et esprit' (Artaud 1989: 7-8).

The iconic relation between a sign and its interpretant plays a fundamental role in the rendition of the sense of discourse and this is also true in the case of interlingual translation. If translation processes stop at the level of conventionality and indexicality, translators will fail their task. In her discussion of translative-interpretive processes, Welby states that the method of language is pictorial, thereby evidencing an aspect of verbal signs that is irreducible to indexicality or to conventionality.

The translator must navigate in the iconic dimension of language and move beyond the conventions and obligations of the dictionary to enter the live dialogue among national languages, among languages internal to a given national language, and among verbal signs and nonverbal signs. The interplay between interpreteds and interpretants, translated signs and translatant signs at high degrees of semioticity necessarily involves iconicity, dialogism and alterity to lesser or greater degrees.

Iconicity implies that the relation between a sign and its object is not totally established by rules and codes, as in the case of symbols, that it does not pre-exist with respect to a code, as in the case of indices, but rather that it is invented freely and creatively by the interpretant. In the case of icons, the relation between a sign and its object is neither conventional nor necessary and contiguous, but hypothetical. And the interpreter, in our case, the translator, must keep account of all this when rendering the original interpretant with the interpretant of another language. When the relation between a sign and its object, and between different types of signs, is regulated by the iconic relation of similarity, affinity and attraction, as Peirce would say, the interpretive-translative processes forming the logico-cognitive and signifying universe at large develop according to the logic of dialogism, alterity, polyphony, polylogism and plurilingualism, to evoke Bakhtin's terminology.

These are all essential properties of language in addition to being necessary as a condition for critical awareness, experimentation, innovation, and creativity. What we claim à propos interlingual translation is also true in the case of intralingual and intersemiotic translation. We know that interlingual translation implies the other two types of translation. Therefore, translative processes always involve interaction among the three types of sign-object-interpretant relations, as identified by Peirce, or in our terminology interpreted-interpretant relations, and the three modalities of translation, as identified by Roman Jakobson (see Jakobson 1959; L. Ponzio 2015). Meanings subsist and flourish in interpretive-translative processes regulated by the relation between identity and alterity in a polylogic and plurilinguistic context, internal and external to a single language. 
In this theoretical framework as delineated by interpretation semiotics, communication is not reductively understood in terms of message exchange. What we wish to underline in the present context is that, as regards in particular the human world, communication converges with the capacity for the unspoken, the unsaid, vagueness, ambiguity, inscrutability, concealment, reticence, allusion, illusion, implication, simulation, imitation, pretence, semantic pliancy, polysemy, polylogism, plurilingualism, alterity - all this presupposes the predominance of iconicity in semiosis and determines the very possibility itself of successful communicative interaction, of successful translational practice.

The translation process is regulated by the logic, or, better, the dia-logic of otherness; ${ }^{4}$ it emerges from and is oriented towards difference. Insofar as this is the case, translation is interpretation, writing, intransitive writing, re-creation: neither translation word by word, letter by letter (verbo verbum reddere, duly criticised by Cicero), nor translation on the basis of sense (St. Jerome's non verbum de verbo, sed sensum exprimere de sensu). The experience of translation, like literary writing, occurs with matter, it is a material process involving letters, the deferral of signifiers.

Translation encounters the twists and turns of language, its equivocations, the indirectness, the obliqueness of its interpretive trajectories. Whether we translate 'by the letter', 'literally' or 'on the basis of sense', we cannot leave the letter, the specificity of the signifier, its materiality, which construes difference in terms of that which cannot be homologated, leveled, or equalized. We cannot translate the letter understood as the materiality, the specificity of the signifier; the letter, that is, the signifying material, insofar as it indicates absolute otherness and excess, is not translatable.

Decisions play on ambiguities, not to dispel them, given that nothing can be decided, but to evidence their signifying import, the signifying import of interpreteds and interpretants, which is further enhanced through the deferral among interpreted-interpretants across other languages. Therefore translation is active, non transparent. It is connected with the work of re-reading and re-writing, re-creating.

Canonical translation is based on the code, convention, authority, authoriality, respect. Contrary to such an orientation, the task of the translator is not to give the impression that the translation is not a translation, but rather to convey the uniqueness, the specificity of the interpretant, its unrepeatability, the sense of its untranslatability, of its signifying materiality, specificity, absolute otherness. Translation should be construed as the specificity of the signifier, 'by the letter'. As such, translational procedure is dominated by iconicity whose signifying value is an "effect" of language provoked by the 'original', by virtue of what Peirce calls its quality.

\section{Dialogic otherness and responsive understanding among interpretants in translation}

To develop language and communication theory from a Bakhtinian perspective means to grasp the otherness dimension of language largely through the experience of literature. The inter-subjective and dialogical dimension of language (the very condition for signifying and communication processes) - which is grounded in the logic of otherness and extralocality and entails the 'ethical' dimension of life and language, it too grounded in otherness logic - tells of the disposition immanent in language to transcend its own limits as artificially imposed by the logic of identity and equal exchange. Literary language theories and philosophical language theories meet in the Bakhtinian perspective: both presuppose plurivocal and dialogical otherness structural to human discourse and as such are open to the ethical dimension of semiosis. Unlike special scientific languages and in line with literary language (especially Dostoevsky's polyphonic novel), philosophical language as well has its specificity in plurilingualism, pluristylism and pluridiscursivity, all capacities that find their sense, are enhanced and developed in relations of reciprocal translatability. So, as mentioned above, though 
Bakhtin does not thematize translation theory directly, translation, insofar as it is inherent, structural to the sign, in fact is essential to his philosophy of the word, of the utterance.

Encounter between the word in the novel and the philosophical word can be clearly traced on a genetical level (Ponzio 2011). Bakhtin traces the origins of the 'polyphonic novel' in 'Socratic dialogue'. In turn, Socratic dialogue can be traced back to the carnivalesque orientation of popular culture which opposes the joyous relativity of a topsy turvy world to the monologism, univocality and dogmatism of hegemonic culture (Bakhtin 1984 [1963]: 106-114). A theory of sign, language and communication with any claim to adequacy should be based on the ethics of otherness, dialogism and translatability. Bakhtin evidences the vocation of philosophy for dialogized pluridiscursivity. This philosophical vocation is in fact the vocation of language. A philosophical perspective on language that focuses on the philosophical perspective of language, as does Bakhtin and his circle, evidences the dialogic capacity of the word - where reference is not only to the philosophical word, but to the word generally in the context of live expression, interpretation and communication.

Far from tending toward totalization or semiotico-philosophical imperialism, to reflect in a philosophical key on verbal and nonverbal expression, and on the translation processes that interconnect them, means to contribute to developing a detotalizing approach to the different areas of knowledge, praxis and human values, considering them from the perspective of their constitution in terms of sign material.

Thanks mainly to results obtained by experimenting with the word's dialogical potential in the laboratory of literary writing, the 'detotalizing' method of inquiry evidences the ethical or, better, 'semioethical' dimension of language. Literary writing highlights the human capacity for the indirect word, for extralocalization, the places of dialogization. Special mention can be made here of the parodic and 'carnivalized' genres of both the oral or written word. All such expressive devices are oriented by the logic of otherness and give full play to the word's internal dialogization, which renders it capable of self-awareness, self-critique and self-derision even, as Bakhtin demonstrates in his 1984 [1965] monograph on Rabelais. That the philosophy of language, or metalinguistics, evidences those places of discourse which resound as pluristylistic, pluridiscursive and plurivocal means to say that it evidences those places where the word is experimented in the encounter with another word, with a word that is other, where the meaning of a word is its translation into that other word and beyond. Translation is at once a modelling device and a communicative procedure that the condition of extralocalization presupposes and that, in turn, presupposes the condition of dialogic listening, responsive understanding and intercorporeity.

To be an adequate interpretant of the original text, the translating text like all interpretant signs not only repeats the interpreted sign, the object of translation, but establishes a relation of 'answering comprehension' (or 'responsive understanding') with it (Bakhtin 1984 [1963], 1990; Bachtin e il suo Circolo 2014). In the translation process, the relation between the text that translates, the interpretant, and the original text, takes place in terms of the logic of dialogism and alterity, in Peirce's terminology in terms of abduction.

In fact, translation involves inferential procedure of the abductive type; consequently, in semiotic terms, as we have seen above, it is dominated by 'iconicity'; from the viewpoint of ethics, to the extent that a good translation is dominated by otherness, abduction and iconicity, it inevitably recalls the associated question of responsibility/responsivity.

The text that translates, the interpretant sign, and the so-called 'original', the interpreted sign, are not connected on the basis of the logic of deduction. The original text is not connected to its translation on the basis of terms and conditions pre-established and predisposed once and for all. A given 'original' text does not inevitably generate a given translation. In other words, the text that translates does not relate to the text object of translation according to the logic of necessity, cause and effect logic. The fact that a text is a translation by no means excludes its autonomy, the possibility of its having a value in itself. 
Let us reiterate then, translation is not mere decodification. To describe the relation between interpreted signs and interpretant signs in terms of decodification means to fall prey to the fallacy according to which to move from one historical-natural language to another, from one linguistic convention to another, simply implies transferral of the same meaning into different containers, or sign vehicles, or signifiers. Translation is not the transition of the 'same' meaning from the original text to the translating text.

As stated earlier, a good translation is one that attempts to establish a relation of responsive understanding with the original. Even more extraordinary is the fact that the meaning of the original is effectively explained and developed through this type of translative/interpretive work, until there appears another translation, another interpretation proposing yet another interpretant which somehow further enhances the meaning 'of the original'.

Even if it occurs according to itineraries that have already been delineated and are habitually followed, therefore as repetition, the interpretive movement is always characterized by the tendency to reach out for the other in the transition from the interpreted sign to the interpretant sign. The interpretant is such not because it repeats the interpreted but because it adds something new to it: between interpreted and interpretant there cannot be a mere relation of equality, absence of differences, total equivalence, substitution of the identical with the identical, not even at the lowest levels of interpretation: we must insist, then, that the interpretant is always the 'same other'.

Even when the interpretant is limited to identification, recognition of the interpreted sign (a given object is recognized as a 'notebook'; a given phonia or graphia as the phonia or graphia of 'notebook'), even when we are at the lowest levels of interpretation (when we read a written text, for example, as an exercise in phonic performance, as recitation), the interpretant sign distinguishes itself from the interpreted sign, it does not simply repeat it, but shifts it in a given direction, risks an opinion, offers something more with respect to the 'original' interpreted sign. In this sense the relation between interpreted and interpretant is a relation of otherness: the interpretant is always something else, different, with respect to the interpreted, and the more interpretation pushes beyond mere interpretation of the interpreted sign and becomes responsive understanding, the more the sign relation takes the character of a dialogic relation.

The interpretant responds to a 'question' posed by the interpreted, takes a stance toward it. Interpreted and interpretant are the question and response in a dialogue, which is internal to the sign, given that the interpreted/interpretant relationship is constitutive of signhood. All interpretive processes in which something carries out the role of sign can be analyzed in terms of 'parts', 'rejoinders' in a dialogue where the interlocutors are the given to be interpreted and the interpretant. From interpretation at the level of perception to the critical interpretation of a written text, all signs present themselves as constitutively dialogical, given that they occur in a relation of alterity with the interpretant sign, without which the conferral of sense would not be possible. The logic of interpretation presents itself, therefore, as dialogic.

The materiality of the text is 'semiotic materiality' which opens to signification in the sense of significance. The text is endowed with its own irreducible autonomy with respect to the meaning that the interpreter attributes to it. And this is the case whether it is a question of the interpreter who 'reads' the text, the 'reader', or of the interpreter who 'produces' the text, the 'author': the text tells of a sense that is other from that conferred upon it by the I that is its interpreter. In this sense, by virtue of its otherness, absolute otherness, the text is endowed with its own objectivity, materiality, capacity for resistance with respect to the interpreting, signifying consciousness.

The sign's alterity determines the limits of interpretation. The limits of interpretation, whether on the side of the 'author' or of the 'reader', are determined by the sign's otherness, that is to say by its objectivity, its semiotic materiality, its autonomy with respect to the interpreting self, whether the latter be the 'reader', or whoever produces the text, the 'utterer' of the text, the 'author'. The problem of 
the limits of interpretation is strictly connected to the problem of the sign's otherness and dialogism and cannot be addressed separately from it.

The constitution of the text is no different from the constitution of identity - whether individual or collective, which is also achieved as a semiotical process and in the relation of otherness - and even less so when there is a question of collective identity. Identity of the self, whether individual or collective, is constituted in the play of deferrals, no differently from the life of a text, whether in the strict sense of the written text, or in the broader sense of the cultural text, verbal but also nonverbal, above all when a question of a text that is capable of flourishing in the 'great time' (Bakhtin), in the deferral among signs, as in the case of the literary text (cf. Petrilli 2012: 53-58, 341-345).

\section{Translation and similarity, between similar and dissimilar}

There is no doubt that a translation must resemble the original. But the idea of resemblance to the original should not end up serving as an obstacle to the capacity for inventiveness, creativity and autonomy of the translation. On the contrary, it should be the condition itself for all this. A translation can make different claims and have different aspirations: it may simply limit itself to following the original text word by word, or it may recreate the original text in another language and do it so successfully as to have value in itself - in the case of a literary text, whether in prose or poetry, it may even reach such high levels in aesthetic value as to become an artwork itself. The relation between interpreted sign and interpretant sign that renders translation best is the 'dialogic' relation.

Just as the repetition of a sequence leads us to believe, as observed by David Hume, that what comes first is the cause of what comes after, and that these terms are connected by a relation of necessity, in the same way familiarity with a text, set frames and habits leads us to believe that the fact of their coming first with respect to their translation implies a relation of cause and effect with that translation, established according to a necessary and unchangeable order. Moreover, this line of thought can even lead to the conviction that any change in a text is a sacrilege: the text can only be that text there, in which case its translation in the last analysis is a fake.

This occurs, for example, in the case of the reader who normally reads Don Quijote in the Spanish original or Divina Commedia in Italian. In the Divina Commedia, Inferno can only begin with the line 'Nel mezzo del cammin di nostra vita' and any variant at all, not only in the sense of transposition into another language, but even of paraphrase in the same language may seem unbearable. Similarly, a reader like Borges even, accustomed to Spanish, may not tolerate variants for Don Quijote other than those - but only to a point - established by the publisher, layout, typesetter. On the contrary, for a reader unfamiliar with ancient Greek, the Odyssey can exist in numerous and different variants, no one of which - even though it is a translation - refers to an original acting as the criterion to measure fidelity. Nor does it make any difference whether these variants are in prose or in verse. The Odyssey, as Borges says, is a sort of international library of works in prose and in verse.

All the same, even though all versions of the Odyssey may appear at once sincere, genuine and divergent, Borges in his reflections on the Homeric translations betrays a weakness for English translations and transpositions which he cites. In fact, Borges associates the Odyssey to English literature which in a sense has always been intimate with this particular epic of the sea. Developing the observations made by Borges, we may remark that for texts familiar only in translation - the original being inaccessible due to linguistic ignorance - the same situations occur as those that concern the relation between the original text and its translation. For example, with reference to the Homeric texts, in Italy, Vincenzo Monti's translation of the lliad carries out the role of original, especially for those who encountered this text for the first time during early school days and have continued reading it, to the point of not wanting to recognize any other version that is not Monti's. And yet, on Ugo Foscolo's ac- 
count, Monti was not worth much as a scholar of ancient Greek. Indeed, it seems that his translation derives not so much from the original as from other translations at his disposal. Foscolo apostrophizes Monti as the 'Traduttor dei traduttor d'Omero'.

À propos Zeno's riddle about Achilles and the tortoise, the question is whether swift-footed Achilles who chases the tortoise but never reaches it is similar to a skilful and relevant translation (Derrida 1999-2000) which also tries to reach the original; and which, like the tortoise, has only a small advantage, that of having taken off first, of starting first. However, precisely because of this advantage, the original, like the tortoise, seems out of reach. The original always comes first.

In any case, it should be remembered that the logoi or argumentations used by Zeno of Elea to deny movement and becoming, like the riddle about Achilles and the tortoise, or the riddle about the arrow, were ultimately intended to support the Parmenidean thesis about unchangeable unity against the appearance of multiplicity (on Zeno's riddles, cf. Colli 1998). This confutation of the existence of the many to assert that only one is possible is also related somehow to the question of translation, of the relation between the only original text and its multiple translations. From this point of view, it is interesting to observe that Zeno's confutation of the multiplicity, as reported by Plato in Parmenides, is based on the notion of similarity, the same notion generally invoked to explain the relation between the text and its translations, as seen above.

Obviously, a translation is not identical to the original: not even Pierre Menard's Quijote by comparison to Miguel de Cervantes's Quijote, though it is 'rewritten' in the same language (cf. Borges $1939 \mathrm{~b})$. If a translation were totally similar to its original, it would be identical, simply another copy of the same text. But a translation must be at once similar and dissimilar, the 'same other'. This is the paradox of translation, the paradox of multiplicity.

To admit the possibility of translation is to admit, contradicting oneself, that something can be at once similar and dissimilar. We could use Zeno's argumentation, against the existence of the many, at once similar and dissimilar, as reported in Plato's Parmenides (1977: 127d-128e), to demonstrate the absurdity of admitting that a text can exist at once as the original text and as the translated text: given that it is impossible for the non-similar to be similar and for the similar to be non-similar, it is also impossible for translations to exist, given that they would be subject to impossible conditions. Instead, expressed with the paradox of Achilles and the tortoise, the 'paradox of translation' consists in the fact that in order to reach the text to be translated, the 'original', the translation must somehow recover the former's advantage which consists in being the first from the very outset.

With reference to Achilles and the tortoise, as reported by Aristotle in Physics (1983 239b: 1420), the argument is that in the race the slowest will never be reached by the quickest. In fact, the pursuer must first reach the starting point of the pursued, so that the slower will always hold a lead. This argument is identical in principle to the paradox about the flying arrow which will never reach its target, because it must cross the infinite halves of the segment representing its trajectory, and this segment is divisible ad infinitum. But in Achilles's argument, unlike that about the arrow which never reaches its target, the distance which remains to be covered is not divided into halves each time he attempts to reach the tortoise.

Borges formulates this argument in slightly different terms (cf. 1932, 1939a): Achilles is ten times faster than the tortoise. Consequently, he gives it a ten metre advantage in the race. But if, as anticipated, Achilles runs ten times faster than the tortoise, it follows that while Achilles runs a metre, the tortoise runs a decimetre; while Achilles runs a decimetre, the tortoise runs a centimetre; while Achilles runs a centimetre, the tortoise runs a millimetre, and so forth ad infinitum. Therefore, swift-footed Achilles will never reach the slow tortoise.

Borges reports and examines various attempts at confuting Zeno of Elea's paradox: that proposed by Thomas Hobbes, John Stuart Mill (System of logic), Henri Bergson (Essay upon the immediate data of consciousness), William James (Some Problems of Philosophy) who maintained 
that Zeno's paradox is an attack not only on the reality of space, but also on the more invulnerable and subtle reality of time, and lastly Bertrand Russell (Introduction to Mathematical Philosophy, Our Knowledge of the External World), being the only attempt Borges considers worthy of the 'original' in terms of argumentative force. Of the 'original' with 'original' placed in inverted commas, because all these successive argumentations, as argumentations in competition with Zeno's paradox, that attempt to equal it in argumentative ability, are nothing but variants or translations of the primary text.

Pierre Menard, author of Quijote, also turns his attention to the riddle of Achilles and the tortoise, as Borges informs us in his equally paradoxical tale dedicated to Menard in Ficciones. In the tale, Menard's Quijote is listed among his works as Les problèmes d'un problème, dated Paris 1917. Menard discusses different solutions, in chronological order, to the 'Achilles' paradox, and in the second edition reports the following advice from Leibniz in the epigraph: 'Ne craignez point, monsieur, la tortue'. Why should we fear the slow tortoise? Because of its advantage, because of the gap, the time-lapse that separates it in space and time, like a gulf, from swift-footed Achilles. To fear the tortoise is to fear the original in translation, which has the advantage of coming first. The text which translates the original is inevitably second.

To fear the original and faithfully respect it: to the point of deciding, as does Menard, that he will not just compose another Quijote, but the Quijote, the unique, the original. Of course, it was not just a question of imitating or copying the original. This would have meant to propose the advantage of the original once again, making of Quijote, as composed by Menard, a second text. Menard had a sacred fear of the original, however he did not fear producing pages that coincided word by word with the words of Cervantes. Menard succeeded in composing chapters IX and XXXVIII from the first part of Quijote. What was his expedient? He gave up competing with Cervantes, who had an obvious advantage simply because he had undertaken to write the same artwork much earlier. And therefore - after attempting to identify with his life, times, biographical context, and thus reach Quijote, having in a sense become Cervantes - Menard decided that the greater challenge was to reach Quijote while remaining Menard, through his own experience as Menard.

Menard's Quijote (a fragmentary artwork; one had to be immortal to bring it to completion) is only 'verbally identical' to Cervantes's Quijote. To prove the difference, in his tale Borges cites a passage from Quijote by Cervantes (part I, chapter IX) and the corresponding passage from Quijote by Menard. Even though these two passages correspond to the letter, the version by Menard, a contemporary of Williams James, clearly resounds with pragmatic overtones. Unlike Cervantes, for Menard, historical truth, discussed in exactly the same terms in both passages, is not what happened but what we judge happened. Achilles can recover the tortoise's advantage and overtake it simply because, even if it started first, he gave it an advantage, he let it be first. All things considered, the tortoise depends on Achilles, and thanks to his generosity for giving it an advantage, Achilles in fact beats it, surpasses it. Moreover, time also plays its part. The style of Menard's Quijote is inevitably archaic and affected, while Cervantes's Quijote is up-to-date and with the times with respect to the Spanish language as it was spoken in his own day.

\section{The paradox of translation is the paradox of the text and of the sign}

The paradox of translation is clearly the paradox of the text and of the sign. After all, if the question of similarity is central to translation, ${ }^{5}$ it is not less important in relation to the text, itself an interpretant before becoming an interpreted sign of other interpretants in reading and translation.

We have seen that the relation between the text and what it's about also presents itself in terms of similarity. And what characterizes the literary text, indeed the artistic text in general, as Bakhtin 
above all has contributed to demonstrating, is that similarity is developed in terms of 'depiction' and not imitation, representation, identification, or unification (cf. Petrilli and Ponzio 1999).

In the case of the text translated across different languages, the relation between the text that translates, the translation, and the original, the translated text, is indirect, mediated, distanced. Translation requires the possibility of withdrawal, the possibility of a vision that is transgredient, an extralocalized relation among signs in the Bakhtinian sense. According to this orientation, the architectonics of the self - like that of the text - and the values associated to it are destabilized, detotalized and reconstructed in relation to the architectonics of the other, as Bakhtin would say. ${ }^{6}$

In terms of reported discourse, translation carries out a practice which involves all historical-natural languages, namely, reporting the discourse of others. And, of course, reported discourse involves both langue and parole. The individual parole is always more or less reported discourse in the form of imitation, stylization, parodization, direct or hidden controversy (according to all the modalities analyzed by Bakhtin in his two different editions of his monograph on Dostoevsky, the first published in 1929, the second in 1963).

The presence of the word of the other in one's own word, the fact that one's own word must make its way through the intentions and the senses of the word of others, and therefore its constitutive dialogic character, favours the dialogic disposition of the translating word. Therefore, because of the inclination of language, indeed of the utterance to report the discourse of others, the inclination to report the word of others from one language to another in the form of translation is already inscribed in speech, that is, in the linguistic function and linguistic translation which make speech possible. The main difficulties that the translator may encounter are those relative to the fact that the utterance or the text he translates belongs to special languages (sectorial or specialized) that he does not know well, or does not handle adequately. But this is no different from the difficulties presented by endolingual or intralingual translation, that is, the passage from one language or jargon to another in the same language. All the same, our claim is that such difficulties cannot be used to justify conceptions in support of the principle of interlingual untranslatability.

Our considerations on the distanced and indirect nature of the translating word with special reference to the literary text, above all the poetic text, most often referred to in support of the thesis of untranslatability, may instead contribute to validating the thesis of translatability. In fact, from this point of view, there emerge relations of similarity between the literary word, therefore the poetic word, on the one hand, and the translating word, on the other. This is not a question of superficial or surface similarity, but rather of homological similarity, that is, similarity in terms of formation and structure, similarity oriented by iconicity.

Both the literary word and the translating word can be distinguished from the word of genres, understood here with Bakhtin (1979) as primary or direct discourse genres. In this case, the word is the word that objectively identifies with the subject that produces it, with the subject's signifying intention. Instead, the literary word belongs to secondary or indirect discourse genres. The literary word is no longer a direct word, one's own word, an objective word that converges with the subject of discourse, as normally occurs in ordinary speech - or, at least, this is the claim. In ordinary discourse in fact the general expectation is for the word and the subject of discourse to converge. Here the subject is objectified in discourse, is finalized in it. On the contrary, secondary genres evidence the indirect character of the word, the word and its shadow, to evoke Levinas once again. The literary word evidences the indirect character of the word, presenting itself as an objectified word, distanced from the self of discourse. It is no longer the word with which the author identifies, but rather the word that is other, such that the utterer can pronounce the pronoun 'l' without identifying with it. This occurs, for example, in the novel narrated in first person, in drama where the playwright has his characters speak directly, even in lyrical poetry and in autobiography where a certain degree of distancing always occurs between the writer and the I of discourse. 'Exotopy' 
understood in the Bakhtinian sense is the condition itself of literariness, as much as of artistic discourse in general.

We have made the claim that translation is indirect discourse masked as direct discourse, which all the same is distanced from its author-translator. As observed above, the translator can say 'l' and nobody expects to identify him with the I of discourse, even when a question of oral and simultaneous translation. Contrary to certain prejudices about the possibility of translating literary texts, especially a poetic text, this capacity for exotopy, distancing, extralocalization potentially present in translation as translation, in translation as such, lead us to claim that translation is in a privileged position with respect to the movement of discourse toward literariness. Such characteristics shared by the literary word and the translating word in fact render them less distant from each other than would be commonly expected.

But 'translatability' does not only imply the possibility of translation in interlingual terms. Translatability also denotes an open relation between a text in the original and its translations-interpretations in the same language. Therefore 'translatability' of a text, like 'interpretability', generally - with respect to which 'translatability' is a special case - also indicates that the translation of a text remains open and is never definitively resolved; that a translated text may continue to be translated, in fact may be translated over and over again, even in the same language into which it has already been translated, and possibly even by the same translator. The sign consistency of the text that is translated, its sign complexity, its semiotic materiality, its otherness and capacity for resistance with respect to any one interpretive trajectory, is evidenced by the fact that the original is not exhausted in the text that translates it. 'Translatability' understood in this sense must also be addressed when reflecting on the limits of translation, as in general of interpretation.

\section{Dialogic and translation in the great time}

The question of translatability implies the question of untranslatability, like two faces of the same process. I am alluding here to the question of translatability, interpretability, expressibility of the untranslatable, of the uninterpretable, of the unexpressible. By virtue of semiotic materiality, of the absolute otherness of the sign, of its capacity for resistance in the face of all attempts at interpreting-translating it, the concept of translatability implies the question of the untranslatable, that is, of that which cannot be englobed, which evades the limits of comprehensibility; it implies the infinite with respect to the finite, the totality; the unsayable with respect to the said in any linguistic system whatsoever, that which cannot be grasped; the unconscious with respect to the conscious, the impossible.

Language, the place of equivocation and misunderstanding, is reinvented always anew at each occurrence, it is the place where something always remains unsaid, the place of the absent. The speech act, assertion, statement necessarily imply leaving something out, something that escapes the will's control, that evades intentional signification, that is not exhausted in saying -absolute otherness. In translation, the other, the absent, the shadow engender new semiosical fluxes formed by interpretant signs which, in turn, resist control and elude the will, signifying intention, purpose, conscious awareness, authority of the ultimate word.

Language (langue/lingua) cannot be reduced to the status of a nomenclature. Otherwise, translation among languages would be immediate, in the sense that each word would have a corresponding concept in its own language and its immediate correlate in another language. But this is not how things stand. The relation is not between words and preconceived ideas, this is not a direct and finalized relation. To assert, to utter, to express oneself, to perform acts through words, speech acts, linguistic acts, means at once to repress, to remove, to silence - all this is clearly revealed by such phe- 
nomena as dreaming, word play, artistic discourse, and symptoms. From this point of view language (langue/lingua) is the condition of the unconscious.

If repression, elimination, removal, silence, the unsaid, the shadow, absolute otherness are the other face of the word, this has consequences for the act of translation, as interlingual translation makes particularly evident. On the one hand, we have mathesis universalis: in other words, common speech, invariability, semiosic fluxes, synechism, energy, progress, succession, return, transitive writing, transcription, continuity; on the other hand, we have mathesis singularis: uniqueness, otherness, fragmentation, death, loss, intransitive writing, variability, unrepeatability, discontinuity. All these factors interact and overlap, evoking each other in uncertain, ambiguous relations, where plurivocality, indetermination and ambiguity prevail.

An act of forgetfulness, oblivion, neglect, denial, a slip, omission, oversight, inadvertence, negligence are all phenomena that show how language is discord and not harmony, dissidence and not a system of oppositional pairs. To evoke Freud, the self is not master in his 'own' home, the speaker is not at home in his 'own' mother-tongue; instead, the self, the speaker, is spoken by a language. The self is nomadic. We are always 'strangers to ourselves' (Kristeva 1988), to the extent that what we share and have in common with each other is the very condition of strangeness, delocalization, that is, absolute otherness.

In the flux of infinite semiosis signs flourish in the dynamics of the interrelation between the logic of continuity and the logic of discontinuity, distinction, discretion, fragmentation, specification, absolute otherness, to evoke together Bakhtin and Levinas. The relation of similarity among signs implies difference, dissimilarity, diversity, diffraction, irreducible alterity. As for the relation between reported discourse and original discourse, the relation between the text that translates and the original text develops in the tension between the centripetal forces and the centrifugal forces that operate in language, as Bakhtin says (1981: 272), between centralization and decentralization, monolingualism and plurilingualism, monologism and polylogism, identity and alterity, the same and the other.

Translation is the condition for the life of signs and of texts, which do non subsist if not in the semiosic process which, in turn, develops in terms of translational processes of deferral from one sign to another, from one utterance to another, from one text to another. From this point of view, interlingual translation is only possible in the tension between translatability and untranslatability.

In Marxism and the Philosophy of Language (1986 [1929]), Voloshinov conceptualizes communication, social relations and verbal language in terms of a dialectic-dialogic interaction between the logic of identity and the logic of alterity. In this general perspective he introduces another two important categories which can be applied to nonverbal sign systems as much as to the verbal: 'theme' (smysl) and 'meaning' (znachenie), what he also denominates 'actual sense' and 'abstract sense' (ibid: 106). The second term in these pairs, 'meaning' or 'abstract sense', refers to the identical, reproducible and immediately recognizable each time the utterance is repeated, as in the case of linguistic elements, phonemes and monemes, which constitute the utterance. According to Voloshinov:

Theme is a complex, dynamic system of signs that attempts to be adequate to a given instance of generative process. There is reaction by the consciousness in its generative process to the generative process of existence. Meaning is the technical apparatus for the implementation of theme. (Voloshinov 1986 [1929]: 100)

'Meaning' thus understood corresponds to signality rather than to 'semioticity' or 'signhood'. In other words, in this particular paradigm, 'meaning' corresponds to the 'interpretant of identification', rather than to the 'interpretant of answering comprehension', to 'plain meaning', rather than to plurivocal meaning. In terms of translational processes, where 'meaning' as we are now describing it dominates, the degree of dialogism and distancing that regulates the connection between interpretant sign and interpreted sign is minimal. 
Instead, 'theme', or 'actual sense' refers to all that is original and unrepeatable in the utterance, to the overall sense, purport, signifying import and to the evaluative orientation as these aspects emerge in any given instance of communicative interaction. 'Theme' accounts for expression, communication and translation among different languages and cultures, among different value systems, in terms of responsive understanding (answering comprehension), multiaccentuality, dialectic-dialogic responsiveness and responsibility.

Bakhtinian dialogics is rich in suggestions for translation theory and practice. It interrogates the literal interpretation of translation understood as transferral, transportation and shift of a text from one language to another, from what could otherwise emerge as one linguistic-cultural prison to another, evidencing its overall implications. Read in the light of Peirce's sign theory, Bakhtinian dialogics contributes to a better understanding of how translation is a practice that frees the sign from the limits of any one sign system and proposes itself, instead, as the condition on the basis of which that sign can develop as a sign.

The concept of 'responsive understanding' not only clarifies that to translate is to interpret, but also that translation involves a dialogic procedure in which understanding means above all to take a stance, to respond, to take responsibility.

To translate is to recreate, to create the conditions for the text to live its life fully, to free it from the limits of language and contemporaneity. As encounter among different historical-natural languages, among special languages, among different cultures, ideologies, and worldviews, among different texts and contexts, whether they are close or distant from each other, in proximity or remote, translation tells us about the condition of joyous relativity in the relation among signs, verbal and nonverbal, where barriers disappear and are no longer an issue. My allusion here is also to those barriers which are presupposed by the theoretician who, while distinguishing between intralingual, interlingual, and intersemiotic translation, forgets that to make such a distinction is only possible by abstracting from the context of the real life of the sign.

The reality of signs and sign processes is the reality of the dialogic relation, of interconnection among signs, intercorporeity, interconnection among bodies. Translation implies interpretation at the highest degrees of otherness, dialogism and responsiveness, which means to say of participative interpretation. All such modalities of living together and constructing texts constitute a translational device that most contributes to the resurrection of the text - which is also the resurrection of the self -, to its continuity, which in fact is no less than the continuity of life in 'the great time'.

\section{NOTES}

${ }^{1}$ On our use of the terms 'interpreted' and 'interpretant', see Ponzio 1990: 15-61; and Petrili and Ponzio 2005: Introduction.

${ }^{2}$ On the terms 'translated' and 'translatant', see Petrilli 2010: ch. 8.

${ }^{3}$ See: http://www.lackuna.com/2012/04/13/5-historically-legendary-translation-blunders.

${ }^{4}$ On the concepts of dialogism and otherness in relation to signs, see Petrilli and Ponzio $(2005,2006,2016)$.

${ }^{5}$ An International Conference on Similarity and Difference in Translation was organized in New York in 2001 (see Arduini and Hodgson 2004).

${ }^{6}$ See Bakhtin 1993 [1920-24] and in Russian original and Italian translation, see Bachtin e il suo circolo (2014: 33-168). 


\section{REFERENCES}

Arduini, Stefano and Robert Jr. Hodgson (eds.) 2004. Similarity and Difference in Translation. Rimini: Guaraldi.

Aristotle 1983. Physics. Books III-IV. Trans. Edward Hussey, Oxford: Clarendon Press.

Artaud, Antonin 1964 [1938]. Le théâtre et son Double, suivi de Le théâtre de Séraphin. Paris: Gallimard.

Artaud, Antonin 1989. L'arve et l'aume, with 24 letters to M. Baberzat. Paris: L'Arbalete.

Bakhtin, Mikhail M. 1929. Problemy tvorchestva Dostoevskogo [Problems of Dostoevsky's work]. Leningrad: Priboj.

Bakhtin, Mikhail M. 1984 [1963]. Problems of Dostoevsky's Poetics. Trans. Caryl Emerson. Minneapolis: University of Minnesota Press.

Bakhtin, Mikhail M. 1984 [1965]. Rabelais and His World. Trans. Helene Iswolsky. Bloomington, Indiana: Indiana University Press.

Bakhtin, Mikhail M. 1979. Estetika slovesnogo tvorchestva [Aesthetics of verbal art]. Moscow: Iskusstvo.

Bakhtin, Mikhail M. 1981. The Dialogic Imagination. Four Essays. Trans. Caryl Emerson and Michael Holquist, Austin: University of Texas Press.

Bakhtin, Mikhail M. 1986 [1952-53]. Speech Genres \& Other Late Essays. Trans. Vern W. McGee, Austin: Austin University of Texas Press.

Bakhtin, Mikhail M. 1990. Art and Answerability. Early Philosophical Essays by M.M. Bakhtin. Trans. Vadim Liapunov, Austin: University of Texas Press.

Bakhtin, Mikhail M. 1993 [1920-24]. Toward a Philosophy of the Act. Trans. Vadim Liapunov. Austin: University of Texas Press.

Bachtin e il suo circolo 2004. Opere 1919-1930. Trans. Augusto Ponzio and Luciano Ponzio. Turin: Bompiani.

Barthes, Roland 1964. Éléments de sémiologie. Communications 4: 91-135.

Barthes, Roland 1982. L'Obvie et l'obtus. Essais critiques. Paris: Seuil.

Barthes, Roland 1993-5. Euvres complètes. Vols. I- III. Paris: Seuil.

Benjamin, Walter 1968 [1923]. The Task of the translator. In: Hannah Arendt (ed.), Illuminations. Essays and Reflections. Trans. Harry Zohn, New York: Schocken Books.

Borges, Jorge L. 1932. La perpetua carrera de Aquiles y la tortuga. In: Jorge L. Borges, Discusión. Buenos Aires: Manuel Gleizer, 151-161.

Borges, Jorge L. 1939a. Avatares de la Tortuga. Sur 63: 18-23.

Borges, Jorge L. 1939b. Pierre Menard, autor del Quijote. Sur 56: 7-16.

Carroll, Lewis 1993. Humpy Dumpty. Trans. Guido Almansi and Giuliana Pozzo. Turin: Einaudi.

Chomsky, Noam 1956. Three models for the description of language. Transactions on Information Theory 2 (3): 113-124.

Colli, Giorgio 1998. Zenone di Elea. Milan: Adelphi.

Deleuze, Gilles 1996 Critica e clinica. Rome: Cortina.

Derrida, Jacques 1961. Preface. In: Artaud Antonin, Il teatro e il suo doppio. Turin: Einaudi.

Derrida, Jacques 1999-2000. Che cos'è una traduzione rilevante? Athanor 10 (2): 25-68.

Hjelmslev, Louis 1961. Prolegomena to a theory of language. Madison: University of Wisconsin Press.

Jakobson, Roman 1959. On Linguistics Aspects of Translation. In: Reuben Brower (ed.), On Translation. Cambridge, MA.: Harvard University Press.

Kristeva, Julia 1988. Étrangers à nous même. Paris: Librairie Arthème Fayard.

Kumar, Amith, P. V. and Milind Malshe 2005. Translation and Bakhtin's Metalinguistics. Perspectives:

Studies in Translatology 13 (2): 15-122.

Levinas, Emmanuel 1994. Les imprévus de l'histoire. Monpellier: Fata Morgana. 
Morris, Charles 1946. Signs, Language, and Behavior. New York: Prentice Hall.

Peirce, Charles Sanders 1931-1958. Collected Papers of Charles Sanders Peirce (1866-1913). Vols. I-VI, Charles Hartshorne and Paul Weiss (eds.), 1931-1935. Vols. VII-VIII, Arthur W. Burks (ed.), 1958. Cambridge (Mass.): The Belknap Press, Harvard University Press. [In the text referred to as CP followed by volume and paragraph number].

Petrilli, Susan 1999. La traduzione crudele di Artaud contro Artaud. In: Susan Petrilli and Augusto Ponzio (eds.), Fuori campo. I segni del corpo tra rappresentazione ed eccedenza. Milan: Mimesis, 273-278.

Petrilli, Susan 2001. II carattere intersemiotico del tradurre. Athanor 4 : 9-19.

Petrilli, Susan 2009. Signifying and Understanding. Reading the Works of Victoria Welby and the Signific Movement. Berlin: De Gruyter Mouton.

Petrilli, Susan 2010. Sign Crossroads in Global Perspective. Semioethics and Responsibility. New Brunswick and London: Transaction Publishers.

Petrilli, Susan 2012. Altrove e altrimenti. Filosofia del linguaggio, critica letteraria e teoria della traduzione in, con e a partire da Bachtin. Milan: Mimesis.

Petrilli, Susan 2014. Sign Studies and Semioethics. Communication, Translation, and Values. Berlin: De Gruyter Mouton.

Petrilli, Susan 2015. Victoria Welby and the Science of Signs. Significs, Semiotics, Philosophy of Language. New Brunswick and London: Transaction Publishers.

Petrilli, Susan and Augusto Ponzio 1999. Fuori campo. I segni del corpo tra rappresentazione ed eccedenza. Milan: Mimesis.

Petrilli, Susan and Augusto Ponzio 2005. Semiotics Unbounded. Toronto: Toronto University Press.

Petrilli, Susan and Augusto Ponzio 2006. Translation as Listening and Encounter with the Other in Migration and Globalization Processes Today. TTR. Traduction, Terminologie, Rédaction 19 (2): 191-224.

Petrilli, Susan and Augusto Ponzio 2016. Lineamenti di semiotica e filosofia del linguaggio. Perugia: Guerra.

Plato 1977. Parmenides. In: Carol Gould (ed.), Plato in Twelve Volumes. Trans. Harold Noth Fowler, Cambridge (Mass.): Harvard University Press.

Ponzio, Augusto 1990. Man as a Sign: Essays on the Philosophy of Language. Berlin: Mouton de Gruyter.

Ponzio, Augusto 2005. Testo come ipertesto e traduzione letteraria. Rimini: Guaraldi.

Ponzio, Augusto 2007. Hypertextuality and literary translation. Semiotica 163 (1): 289-309.

Ponzio, Augusto 2011. La filosofia del linguaggio. Segni, valori, ideologie. Bari: Giuseppe Laterza.

Ponzio, Luciano 2000. Icona e raffigurazione. Bachtin, Malevich, Chagall. Bari: Adriatica.

Ponzio, Luciano 2002. Visioni del testo. Bari: Graphis.

Ponzio, Luciano 2009. L'iconauta e l'artesto. Configurazioni della scrittura iconica. Milan: Mimesis.

Ponzio, Luciano 2015. Roman Jakobson e i fondamenti della semiotica. Milan: Mimesis.

Sebeok, Thomas A. 1975. The Semiotic Web: A Chronicle of Prejudices. Bulletin of Literary Semiotics 2: $1-63$.

Sebeok, Thomas A. 1986. I Think I Am a Verb: More Contributions to the Doctrine of Signs. New York and London: Plenum Press.

Sebeok, Thomas A. 1994. Signs. An Introduction to Semiotics. Toronto: Toronto University Press.

Sebeok, Thomas A. 1995. Semiotics and the Biological Sciences: Initial Conditions. Discussionì Papers

17. Budapest: Collegium Budapest/Institute for Advanced Study.

Sebeok, Thomas A. 2001. Global semiotics. Bloomington: Indiana University Press.

Torop, Peteer 2002. Translation as Translating as Culture. Sign Systems Studies 30 (2): 593-605.

Voloshinov, Valentin N. 1986 [1929]. Marxism and the Philosophy of Language. Trans. Ladislav Matejka and Irwin Robert Titunik, Cambridge (Mass.): Harvard University Press. 
Watt, W.C. 2011. Birth of a notion. In: Paul Cobley, John Deely, Kalevi Kull and Susan Petrilli (eds.), Semiotics Continues to Astonish. Berlin: De Gruyter Mouton, 263-270.

Welby, Victoria (1983 [1903]). What is Meaning? Studies in the Development of Significance. Amsterdam and Philadelphia: John Benjamins.

Zbinden, Karine 2006. The Bakhtin Circle and Translation. The Yearbook of English Studies 36 (1): 157-167.

Susan Petrilli is Professor of Philosophy and Theory of Languages, Department of Letters, Languages, Arts, Italian Studies, Comparative Cultural Studies, The University of Bari “Aldo Moro", Italy.

Email: susan.petrilli@gmail.com 